\title{
How to Revise, and Revise Really Well, for Premier Academic Journals
}

Peter LaPlaca, University of Connecticut ${ }^{1}$

Adam Lindgreen, Copenhagen Business School and University of Pretoria's Gordon Institute of Business Science $^{2}$

Joëlle Vanhamme, Edhec Business School ${ }^{3}$

C. Anthony Di Benedetto, Fox School of Business, Temple University ${ }^{4}$

${ }^{1}$ Professor emeritus Peter LaPlaca, 24 Quarry Drive, Vernon, CT 06066, USA. E-mail: pjlaplaca@comcast.net.

${ }^{2}$ Professor Adam Lindgreen, Department of Marketing, Copenhagen Business School, Solbjerg Plads 3, 2000 Frederiksberg C, Denmark and University of Pretoria's Gordon Institute of Business Science, 26 Melville Road, Illovo, Johannesburg, South Africa. E-mail: adli.marktg@cbs.dk.

${ }^{3}$ Professor Joëlle Vanhamme, Edhec Business School, 24 avenue Gustave Delory, CS 50411, 59057 Roubaix Cedex 1, France. E-mail: joelle.vanhamme@edhec.edu.

${ }^{4}$ C. Anthony Di Benedetto, Fox School of Business, Alter Hall 523, 1801 Liacouras Walk, Philadelphia, PA 19122-6083, USA. 


\begin{abstract}
Most of the premier academic journals in all fields routinely have rejection rates of $80 \%, 95 \%$, or higher. All journals prefer articles that make significant contributions to the field. Revising a manuscript and responding properly to the comments of reviewers and editors often is challenging. This article discusses how to revise effectively a manuscript according to the (minor or major) comments of reviewers and editors for premier academic journals. We provide a series of tips for helping the authors in their endeavor, making the process less arduous and improving the possibility of a positive outcome.
\end{abstract}

Keywords: academic writing, premier academic journals, publication success rate, reviewing, revising. 


\section{INTRODUCTION}

To young scholars, the review process seems to be a confusing black box. In goes the manuscript, something happens over the course of a couple of months, and out comes a response - the editor's decision. To all of us in academia, the process is familiar. The author carefully writes and proofreads, then sends his or her best effort to the editor of the targeted journal. Then the wait begins. Even if the website clearly states a typical turnaround time of two months, the delay seems unbearable. The author may turn to online tracking every so often, if available from that journal. The manuscript is with the reviewers. Then eventually the manuscript is in the hands of the editor, and a decision e-mail will be coming soon. The good news is that the author has been invited to revise and resubmit the manuscript for further consideration! Then the bad news sinks in. Three reviewers, six single-spaced pages of critiques and recommendations from each reviewer, some comments are mutually inconsistent, a couple of the comments seem impossible, and Reviewer 3 particularly seems to dislike the manuscript for some reason. After the initial emotional shock, and maybe a couple of days to sleep on it, the author reads the reviews again, dedicated to improving the manuscript and getting that acceptance on the next round.

What happens inside that black box can seem mysterious and a little intimidating. The objective of this article is to provide guidance on the revision process. We lay out some of the beginners' mistakes that can lead to desk rejection. We provide a look inside the review process at Industrial Marketing Management. We also provide strategies on how to respond to reviews, whether they are an invitation to revise and resubmit or an outright rejection. We hope that the guidance provided here helps prospective authors avoid the desk-reject decision, and develop revised manuscripts and replies to reviewers that ensure the reviewers keep liking the manuscript and the editor keeps moving the manuscript toward acceptance.

We structure the remainder of this article in the following sections. First, we explore the review process and make suggestions on how the manuscript does not get rejected by the editor even before the manuscript has a chance to reach the reviewers. Second, we go further into the editor's desk reject decision, specifically at Industrial Marketing Management, noting how and why this decision has become a bigger factor in recent years. Third, we examine the reviewers' rejection decision, and the author's next best steps in this case. Fourth, we lay out suggestions and recommendations to authors on how to respond to the invitation to revise and resubmit their 
manuscript. Fifth, we present briefly the publication process. Finally, we conclude with a summary of recommendations, particularly suited to the young academic researcher.

\section{THE REVIEW AND REVISION PROCESS}

Before authors submit their manuscript, they should avoid an early rejection due to the fact that their manuscript does not fit the journal's mission. Thus, we advise strongly that authors read carefully the description of what the mission of the journal is (i.e., the journal that the authors want to submit to), as well as the editorials published by the current editor(s). These editorials are available on the journal's website. Editorials often highlight what editors find important to consider before submitting a manuscript. Reading the editorials might seem to be self-evident, but manuscripts frequently are desk-rejected by the editor (more on this below) because there is simply no fit to the journal's mission. A careless author might send a consumer-psychology article to Industrial Marketing Management after having done a quick search through a list of academic journals with "marketing" in the name, without noticing that the manuscript does not fit Industrial Marketing Management's mission of publishing manuscripts pertaining to businessto-business marketing. Obviously, a mistake like this easily is avoided: check out the targeted journal, read the statement of mission or journal scope, download a couple of recent articles, and assess the fit with the journal's scope.

Other reasons for an early rejection are that the manuscript is of limited interest, or that it covers local issues only (e.g., sample type, geography, specific product, etc.). It needs to be stated explicitly at the outset what the manuscript's importance and implications are; and the manuscript needs to be interesting and relevant. Authors need to engage in the journal's conversation, for example, by citing relevant articles from the journal. Manuscripts also should not be a routine application of well-known methods, present a minor incremental advance in literature, or be limited in scope. Even in the case where manuscripts make novel and significant advances in literature, authors may not have explained these advances in an evident manner or justified these advances sufficiently well. There thus could be a note to the editor which people have commented on the manuscript prior to official submission because this shows seriousness and that at least these people found merit in the manuscript.

Reasons for an early rejection may also stem from the way that manuscripts are prepared. Does the manuscript meet submission requirements? Does the manuscript provide an appropriate coverage of relevant literature? On the journal webpage, there will be author guidelines on how 
to organize and present the manuscript. Some journals require Roman or Arabic numerals for section and sub-section headings; some journals do not. Many journals prefer reference callouts in the text in the form of (Smith et al., 2012), while others prefer a number in brackets like [1]. Some journals require a discussion of managerial implications, while others do not. All journals have a desired style for the reference list; most (but not all!) will insist that the references are in alphabetical order. In all cases, authors must adhere closely to the guidelines. It is worth spending an hour or two changing reference style to agree with journal requirements because it shows that the author took the time to do the "little things" right, and this always makes a good impression on the editor.

Another frequent question is about writing quality and style. Is the level of English in the manuscript of unacceptable standards? If necessary, we recommend that authors send their manuscript for professional copy editing. (All major journals provide language assistance; just look at their websites.) A couple of small style errors will not sink a promising article, but if the English style is so poor that it becomes a distraction, or even makes it difficult to understand the point actually being made by the authors, it will result in a rejection. Have the manuscript checked by a professional to minimize the chance of a desk rejection. We refer the readers to a previous article, published in Industrial Marketing Management that discusses how to write really good articles for premier academic journals (LaPlaca, Lindgreen, and Vanhamme, 2018). That article discusses good practices to increase the chances of getting published.

The review and revision process for Industrial Marketing Management is depicted in Figure 1. When editors receive a manuscript, they acknowledge having received the manuscript before they identifiy three appropriate and available reviewers. Different ways are used to do that (often a combination of these ways). For example, editors may invite authors mentioned in the reference list, find reviewers using keywords from the journal's database, or consult experts in the field they know already or find through a google search. A blind copy of the manuscript is sent to each reviewer, and the reviewers are asked to confirm that they are willing to review the manuscript. (If a reviewer for whatever reason is not willing to review, an invitation is sent to another reviewer.) Reminders, if necessary, are sent to reviewers after 60 days, 90 days, and 120 days so that eventually the editors have received three reviews of the manuscript. Reviewers are expected to evaluate the manuscript constructively and then suggest a decision to the editor (this is, however, only a suggestion, as the editor is the one who makes the final decision). 


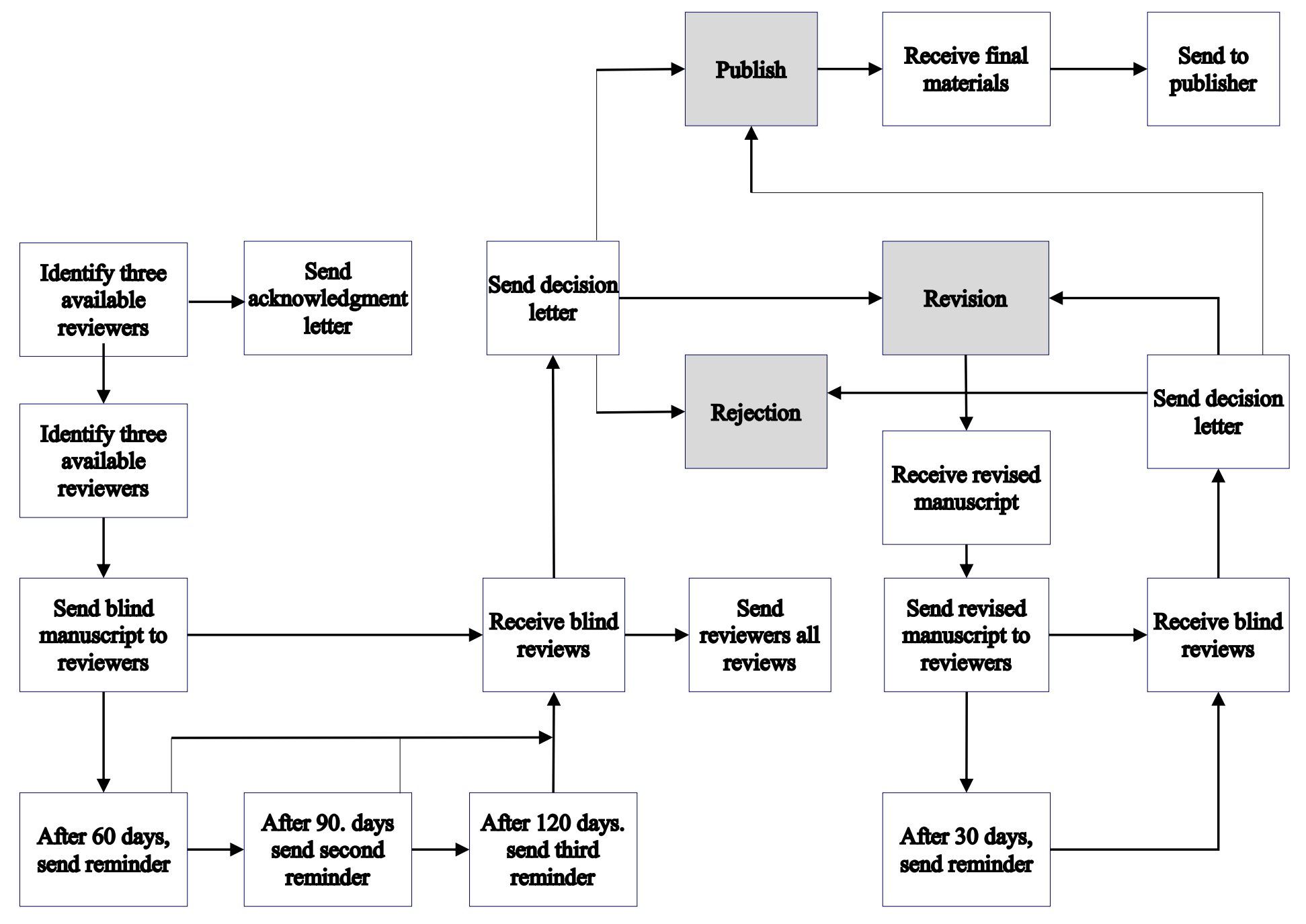

Figure 1: The review and revision process 
The editors then read all reviews, make their decision, and send a letter to the author(s) including all three reviews. A copy of this letter and the three reviews also are sent to each of the reviewers. (Doing this ensures that more inexperienced reviewers learn how other reviewers evaluate the same manuscript.)

While authors all want to receive acceptance letters when submitting their manuscripts to journals, it is quite rare that this happens on the initial submission. When a manuscript is not desk rejected, what usually happens is that the reviewers recommend that the manuscript be either rejected or invited for a (major) revision. ${ }^{5}$ Let us next consider the first scenario.

\section{Editor's Manuscript Desk Rejection}

The editor carries out an initial evaluation of the submitted manuscript. In doing so, the editor identifies whether the manuscript sufficiently satisfies editorial guidelines of Industrial Marketing Management, provides implications for the domain of industrial marketing management, and has some likelihood to be evaluated favorably by the reviewers.

When a submitted manuscript fails to satisfy one or more of the above criteria, a decision is made to reject the manuscript instead of sending it to reviewers as a part of the journal's double blind-review process. The reason for a desk rejection mostly is associated with the uncertain theoretical contribution(s) that the manuscript may provide to current understanding of industrial marketing management. The contributions would be considered as relatively limited and do not exist to the degree that would be expected for a manuscript to be considered for publication in Industrial Marketing Management. In this respect, authors need a much better justification for why they examine the given research issue(s). What new conceptual insights will be derived from their examination, and how do these insights move research on industrial marketing management? For example, just because limited research may have examined a chosen aspect of industrial marketing management in a particular country this is not necessarily a reason for undertaking further research. There must be a stronger reason for why to do so, as otherwise the manuscript falls short in providing a solid conceptual contribution to industrial marketing

\footnotetext{
${ }^{5}$ Reviewers, in fact, can recommend one of five decisions: a) publish as is, b) minor revision and publish, c) minor revision and re-review, d) major revision and re-review, and e) reject. In this article, we have grouped b, c, and d together under the heading 'reviewers' manuscript (major) revision'.
} 
management literature. In this scenario, the editor desk rejects the manuscript because he believes it would be a disservice to subject the manuscript to a lengthy review process when ultimate acceptance appears to be very unlikely.

Reviewers play an important role in the remaining two scenarios, which we consider next. Before doing that, however, we first want to spend some time on what it means to be a reviewer.

Industrial Marketing Management has grown in many ways over the last decade: more submissions each year, more rejections, more articles published, more pages each year, better quality articles being published, more citations, and an increasing impact factor and reputation. The great bulk of the effort to achieve this quality growth has come from the more than 400 people who donate their time and talent to serve as reviewers for the journal. But what does it mean to be a reviewer, especially for a premier academic journal?

Yes, reviewers do evaluate submitted manuscripts and recommend acceptance, rejection, or revision. Revised manuscripts are then re-reviewed at least once and often two, three, or four times. More important than recommendations, however, are the critical comments to the authors. Good reviewers take this responsibility very seriously. Despite their own teaching and research obligations, reviewers take significant time to provide authors with constructive critiques on their submissions, even for manuscripts they recommend be rejected. For Industrial Marketing Management, it is quite common that three reviewers each will send in three-to-five pages of comments, and when the editor puts this all together for the authors, the resulting letter can be eight-to-12 pages of feedback. (Of course, this is accomplished through our web-based editorial system so there are no real "pages.”) Reviewers also provide suggestions for additional research that would improve the manuscript, or they provide additional references that the authors did not include in their manuscript. Reviewers suggest improvements to tables and figures to better convey information to readers, and reviewers even make recommendations to improve the manuscript's title. Often, we have received thank you e-mails from authors of rejected manuscripts who - although they had their manuscript rejected-still appreciate the quality of the reviews they received.

Another obligation of reviewers is to render their recommendations and constructive criticism in a timely fashion. At Industrial Marketing Management, we ask that all reviews be completed in four to six weeks from the time they are sent to the reviewers. Most, but not all, reviewers do meet this expectation. To keep authors waiting three or four months or more is quite unfair and 
disrespectful to the authors and to the editors. If reviewers cannot complete their assigned reviews by the requested deadline, whether due to workload or lack of qualifications for the specific manuscript, they should let the editor know immediately so that an alternative reviewer can be invited.

The general criteria that reviewers consider in their evaluation of a manuscript (both when they recommend the manuscript be rejected and when they recommend acceptance subject to [major] revisions) are the extent to which a manuscript:

- Is pertinent to industrial marketing management.

- Makes a significant contribution to theory.

- Has a good likelihood of being cited.

- Is founded on a sound theory.

- Presents new or existing material in a new light.

- Presents its contents in a logical flow.

- Presents its contents with clarity.

- Has interest as a case study.

- Addresses properly managerial implications.

- Includes an adequate review of previous literature.

For empirically based manuscripts, reviewers additionally consider the following:

- Which method has been used?

- Are hypotheses properly developed?

- Is the sample size appropriate?

- Is the sample representative?

- Is the analysis appropriate?

- Is the analysis presented clearly?

- Does the analysis truly support the conclusions?

\section{Reviewers' Manuscript Rejection}

Often, at least for Industrial Marketing Management, authors receive notification from the editor rejecting the submission based upon the reviewers' recommendations and comments. This notification provides reviewer and editor feedback as to why the manuscript was rejected. Again, the most common cause is lack of contribution. When selecting a topic to research, authors need 
to make sure the research question is one of wide interest to the field of industrial marketing management.

If authors believe a reviewer has misunderstood what they have tried to say in their manuscript (note: it is, of course, most of the time, if not all the time, the authors' own fault for allowing a misunderstanding; misunderstandings often come from unclear writing or explanations), they should contact the editor immediately and explain their perspective and why they believe (in light of what their intent was) the reviewers' comments are not valid. Before doing so though, it might be a wise idea to ask colleagues what they objectively think of the comments (without telling them that you disagree, as this, of course, would biase the colleagues' answer). The editor then will discuss this with the reviewers or may seek the opinion of an expert in that specific aspect (for example, a specific analytical method). If different reviewers provide conflicting comments (such as asking for mutually exclusive changes), authors should point this out to the editor who then may provide suggestions as how to resolve the conflict. Ultimately, however, it is for the authors to satisfy the reviewers. It should be noted, though, that sometimes reviewers merely suggest different possibilities to improve the manuscript or solve an issue in the manuscript. Furthermore, it could be that the suggestions made by the reviewers are equally good, but mutually exclusive. In that case it is up to the authors to select the appropriate avenue to improve the manuscript. Often, there are different possible ways to tackle the same issue, and the authors are the ones who best know which solution will be most appropriate. Authors should, of course, clearly explain in their revision note why the approach they chose is better than alternatives. In the extreme, when the reviewer comments are incompatible (one literally says the manuscript should be longer and another says it should be shorter), or the author feels the reviewer clearly has missed a point or made a recommendation that is infeasible, the author should contact the editor directly for clarification.

Although a rejection always is disappointing, it is not the end of the world. Authors should try to understand why their manuscript was rejected. The reviewers have taken the time necessary to provide important feedback that can be used when revising the manuscript so that it can be submitted somewhere else. Authors should re-evaluate their work, taking in the reviewers' feedback, and then decide whether it is appropriate to submit the manuscript - after revisionelsewhere. One possible strategy could be that the authors enclose a cover letter, declaring that the manuscript was rejected at another journal (mention which one), include the reviewer reports 
and a detailed letter of response, discussing how each comment has been addressed. Authors also should explain why they are resubmitting the manuscript to this new journal, for example, this journal is a more appropriate journal, the manuscript has been improved as a result of its previous reviews, among other things.

We mention the above strategy because it could be that the manuscript is sent to the same reviewer who previously rejected the manuscript for another journal. It might seem to be a case of extremely bad luck to get the same (negative) reviewer at two different journals, but the author should keep in mind that the editor will be sending the manuscript to experts in the subject area, and there may be only a limited number of reviewers available. Reviewers will remember reading a manuscript they previously had rejected and will not look fondly on the manuscript if they discover that none of their suggested improvements was attempted, and the manuscript contains the same flaws as before. Even if not all of the recommended changes are made, authors should recognize that because two or three of the top academics in the world, in his or her own research area, have reviewed the manuscript and made suggestions for improvement, some of these suggestions certainly should be followed to improve the manuscript before resubmitting elsewhere. One of the authors of this manuscript was Editor-in-Chief of two journals when a manuscript was rejected at Journal A and was quite surprised to see the same author submit the same manuscript (without any revisions or changes whatsoever) later that same day to Journal B! This is the behavior of an inexperienced author who failed to appreciate the opportunity to learn from the suggestions included in the negative reviews and improve the manuscript. (Needless to say that the manuscript immediately was desk-rejected.)

\section{Reviewers' Manuscript (Major) Revision}

When authors receive a revise and resubmit letter, they should take time to digest the letter before beginning the task of revising the manuscript. We suggest they put the letter aside for a few days before re-reading it. This re-reading is to absorb the overall tenor of the letter, as well as the main points of the editor and the reviewers. It is most likely that authors will find it difficult to accept that their manuscript is being critiqued and will therefore feel defensive, resentful, or even angry when they first receive the letter. It is good advice to put the letter away until the negative emotions have subsided, then starts the revision process objectively and with an open mind to the comments and critiques. 
Although authors may not feel that way when they receive the editor's decision with the reviewers' comments, reviewers and editors try to perform the process constructively. This means that authors should try to see the revision process as a way, or even as an opportunity, to improve their work. It really is a matter of mindset. Keep in mind that the letter is a "revise and resubmit" letter and not a "respond to reviewer comments" letter. While a revision (and improvement) will involve responses to reviewers' comments, merely responding to them is insufficient to really improve the manuscript.

It is much easier for authors to see comments in a constructive way when they believe that reviewers try to help out rather than when the authors are upset or disappointed because they feel reviewers are being unfair. Some comments may sound harsh at times, but authors always should try to understand where the comments come from. It could be, for example, that the manuscript was not written very clearly and that reviewers therefore had a hard time understanding what the authors tried to say. Thus, adopting the proper mindset is really key for revising a manuscript successfully. If authors are flexible in their attitude and willing to accept criticism in a positive light, revising a manuscript will become a much simpler task than if authors are unable to accept criticism and resist the thought that their manuscript needs improvement. If the editor's decision was a "revise and resubmit," authors always should attempt to revise irrespective of the work required, as there is fair chance that if the manuscript is revised competently it has a chance of being accepted eventually. Also, sometimes sections or new studies added to the manuscript in response to reviewers' comments eventually become the most interesting parts of the later accepted manuscript.

The next re-reading is to look at the manuscript with fresh eyes and look at the specific points raised by the reviewers. Authors should remember to revise the whole manuscript, not just the parts that the reviewers point out. Although a reviewer may mention specific issues only, when addressing these issues it could mean that the authors need to add new research, improve the flow of the entire manuscript, revise tables and figures elsewhere in the manuscript, among other things.

Authors should block out enough time in their agenda for their revision because a good revision is a demanding task, and authors should seek to carry out the revision earlier rather than later (right away, if possible). However, some improvements do require significant amounts of time such as collecting additional data, redoing analyses, etc. Don't rush this or take shortcuts. 
Then authors should plan on how they will address the issues raised in the letter. Authors should remember that a revision is an opportunity to improve the entire manuscript, not just to respond to specific points raised by the reviewers. More importantly, with reviewers having provided precise suggestions and comments, authors will know exactly what to address, but not immediately how to do so. Authors should start by asking: "now that we have received some reaction to our manuscript, how can we really make it as good as possible?" Maybe the original manuscript was too broad and tried to accomplish too much. How can the manuscript be better focused? What does the manuscript need to make a real contribution to industrial marketing management? In answering these questions, authors can define more precisely the research question and the knowledge gap that their manuscript attempts to solve. Notice that the words "question" and "gap" are singular; too many manuscripts try to incorporate multiple research questions and knowledge gaps and, in doing so, fall far short of developing a quality manuscript. To demonstrate what truly is required to revise a manuscript, let us outline a quality response letter sent to the editor with a revised manuscript (note: the letter the authors received was a "revise and resubmit" letter, not a "respond and resubmit" letter. Revision takes much more that merely responding to reviewer comments). ${ }^{6}$ Authors should write their response letter in a way that the letter can be given to the reviewers without the editor having to rewrite the letter. Throughout the whole letter, authors should strike the right tone: polite and grateful, confident, and robust. We write this because sometimes a review can be harsh, but it is important that authors do not take reviews personally. (Remember that this is a double-blind process; reviewers do not know who the authors are; they simply are commenting in the manuscript as they received it.) Instead, successful authors engage with the comments and rewrite their work, they deliver their revisions in a timely manner, and they explain their work and engage with the reviewers.

The first paragraph should thank the editor and the reviewers for the opportunity to improve the manuscript and for their valuable feedback. Authors may take the opportunity to highlight particularly valuable comments.

\footnotetext{
${ }^{6}$ You will note that we make this point several times in this article. Why? Because it is very frequently overlooked by authors; they simple respond to reviewer comments rather than truly revise and improve their manuscript.
} 
The second paragraph should summarize the overall improvement made to the manuscript. This might include large scale changes to the manuscript's structure, purpose, breadth, and/or development. This paragraph sets the framework for the improvement (also known as the revision) and demonstrates to the reviewers that the authors have made a significant effort to improve their manuscript. It also gives the authors a chance to show how the improved manuscript makes a contribution to the field, and why the manuscript should be accepted. This is also a good opportunity to show where the manuscript has been improved in places other than those addressed by the reviewers, or to show how the authors have incorporated new research that has appeared since their original submission to the journal.

Following this, the authors should show clearly how they have responded to specific suggestions and comments offered by the reviewers. Reviewers should not have to work to see how authors changed the original manuscript in response to their comments. One way to achieve this clarification for the reviewers is to devote sections of the response letter to each reviewer. (In fact, authors simply can copy the entire decision letter into their own letter and then insert their interpretations and responses where appropriate.) Each section should be labeled clearly (e.g., Response to Reviewer A) and show each comment made by the reviewer, the authors' interpretation of why the reviewer made this comment, how the authors approached the revision, and the exact change(s) made to the manuscript. Authors can use different color fonts or use normal, boldface, or Italics to distinguish reviewer suggestions and comments, and specific changes. If multiple reviewers made the same comment, this will be repeated in the section dealing with responses to that reviewer's comments. The rule here is to respond to every single one of the reviewers" comments. One option is to start each reply with a comment like "Done" or "Thank you, this has been corrected" and be sure to mention the page number where the changes can be found in the revised manuscript.

Occasionally, a reviewer may be undertaking research quite similar to that described in the manuscript and which would integrate nicely with it. The reviewer may contact the editor to indicate this possibility and request the authors' identification after the process has ended. When this occurs, the editor will contact the authors mentioning this possibility and, only if the authors approve, will identify them to the reviewer.

The closing paragraph is another opportunity to explain the manuscript's overall improvement. Some journals have guidelines for replies to reviewers, which, needless to say, 
should be adhered to. For example, some journals require that the changes in the revised manuscript be highlighted in a different color so that the reviewers can find them easily. Other journals may impose a maximum number of pages to a reply to reviewers. (It hardly seems necessary to write a 70-page reply accompanying a 30-page revised manuscript, and no, the reviewers will not be impressed just by the length of the reply.) Of course, the author must follow any such guidelines when writing the reply to reviewers. Taking a disciplined approach to manuscript improvement easily can eliminate one or two rounds of revision and review for a manuscript.

In this step of the review process, the editor expects authors to address all the issues raised, but not necessarily to agree with all the reviewers' comments and suggestions. The reason for this is that academic research should encourage debate and the exchange of information; the academic review process should do the same. Authors therefore should provide a scientific response to the comments they accept; and a convincing, solid, and polite rebuttal to the points where they believe the reviewers' suggestion would not help improving the manuscript (that is, the authors may disagree with the reviewers or even if they do agree, they may feel that the suggestion does not improve the manuscript or takes it in a direction that the authors do not want to pursue).

If authors believe that a comment by a reviewer is based on a misunderstanding, it is best politely to suggest that the text's lack of clarity might be the source of the issue raised (and apologize for it) and then rewrite the text in such a way that there cannot be any confusion. A similar approach can be used for comments that may be based on insufficient knowledge on the part of the reviewer. Authors need to make sure that readers understand what has been done and what has been written; if reviewers do not understand, chances are that readers might not understand either! Thus, authors need to provide simple explanations in the text that all readers will be able to understand. It is the authors ownfault if their text is too technical and uses too much jargon.

As long as authors work to enhance the rigor and quality of their contributions, editors usually encourage such interactions. In this context, editors aim to be true "editors" rather than "review collectors" so that they will adjudicate as necessary any significant disagreements across reviews or between reviewers and authors; indeed, the final publication decision is that of the editor. Once authors think they have gone through all comments and revised their manuscript the 
best they could, they should put it aside for a day or two and then read the manuscript and notes a last time before sending it all to copy editing (if needed) and resubmit it to the journal. Before resubmitting, it is also advised to check whether new relevant articles have appeared in the literature since the time of the first submission. Adding these articles likely will enhance the manuscript by providing a more complete and up-to-date view of the topic.

In general, not all comments in a review are equally important from the reviewer's viewpoint. Some of the comments are merely suggestions for improvement, and the reviewers leaves it up to the authors to decide what to do. However, in some instances, the reviewer deems a response to one or two particular comments as extremely important and a necessary condition for publication of the manuscript. Authors should make sure that they find out which comments are really key and address those comments very convincingly (it may be that authors need to collect additional data, re-run all analyses, rewrite all the theory because another theory is more suitable, and so on; these are all fairly common requests for major and risky revisions).

Because reviewers' opinions sometimes vary, editors expect reviewers to offer clear, wellsubstantiated comments. However, those comments also should focus on the substance of the submission content and their review, rather than the reviewers' beliefs about the most appropriate publication decision. That decision rests solely with the editor and may, in some cases, differ from the reviewers' recommendations.

Finally, although not always possible, Industrial Marketing Management aims to reach a final acceptance decision in no more than two rounds of reviews. Of note, however, is that editors ultimately are interested in publishing the best possible articles; thus, authors should ask for additional time to do their revisions if they need this. It is important to ask for an extension on time and not wait until the deadline for resubmitting has passed. Also, if authors ask for an extension, they should make sure to complete the revision before the end of the extension and not ask for yet another extension as this shows bad planning or lack of professionalism on the authors' part.

After the editors have received the revised manuscript, they send it out to those reviewers who had asked for revisions to be made (see Figure 1). After 30 days, if necessary, the reviewers will receive a reminder that their review is due. When the reviews are in, a decision is made as to whether to publish the manuscript as is, ask for further revisions, or reject the manuscript. Eventually, the manuscript will be accepted or rejected. Throughout the whole revision process, 


\begin{tabular}{|c|c|c|c|}
\hline Reviewer A & Reviewer B & Reviewer C & Decision \\
\hline Reject & Reject & Reject & Reject \\
\hline Reject & Reject & Anything & Reject \\
\hline Reject & $\begin{array}{l}\text { Total rewrite and } \\
\text { resubmit }\end{array}$ & $\begin{array}{l}\text { Total rewrite and } \\
\text { resubmit }\end{array}$ & Reject \\
\hline Reject & $\begin{array}{l}\text { Total rewrite and } \\
\text { resubmit }\end{array}$ & $\begin{array}{l}\text { Major rewrite and } \\
\text { resubmit }\end{array}$ & $\begin{array}{l}\text { Reject, if editors don't believe the } \\
\text { authors can satisfy the reviewers' } \\
\text { objections; otherwise revise and } \\
\text { resubmit }\end{array}$ \\
\hline Reject & $\begin{array}{l}\text { Major rewrite and } \\
\text { resubmit }\end{array}$ & $\begin{array}{l}\text { Major rewrite and } \\
\text { resubmit }\end{array}$ & $\begin{array}{l}\text { Reject, if editors' don't believe the } \\
\text { authors can satisfy the reviewers' } \\
\text { objections; otherwise revise and } \\
\text { resubmit }\end{array}$ \\
\hline Reject & $\begin{array}{l}\text { Major rewrite and } \\
\text { resubmit }\end{array}$ & $\begin{array}{l}\text { Major revision and re- } \\
\text { review }\end{array}$ & Revise and resubmit \\
\hline $\begin{array}{l}\text { Total rewrite and } \\
\text { resubmit }\end{array}$ & $\begin{array}{l}\text { Total rewrite and } \\
\text { resubmit }\end{array}$ & $\begin{array}{l}\text { Total rewrite and } \\
\text { resubmit }\end{array}$ & $\begin{array}{l}\text { Reject, if editors don't believe the } \\
\text { authors can satisfy the reviewers' } \\
\text { objections; otherwise revise and } \\
\text { resubmit }\end{array}$ \\
\hline $\begin{array}{l}\text { Total rewrite and } \\
\text { resubmit }\end{array}$ & $\begin{array}{l}\text { Total rewrite and } \\
\text { resubmit }\end{array}$ & $\begin{array}{l}\text { Anything other than } \\
\text { reject or Total rewrite } \\
\text { and resubmit }\end{array}$ & Revise and resubmit \\
\hline $\begin{array}{l}\text { Anything other than } \\
\text { reject or Total } \\
\text { rewrite and } \\
\text { resubmit }\end{array}$ & $\begin{array}{l}\text { Anything other than } \\
\text { reject or Total rewrite } \\
\text { and resubmit }\end{array}$ & $\begin{array}{l}\text { Anything other than } \\
\text { reject or Total rewrite } \\
\text { and resubmit }\end{array}$ & Revise and resubmit \\
\hline
\end{tabular}

Figure 2: Editors' decision "rule" 


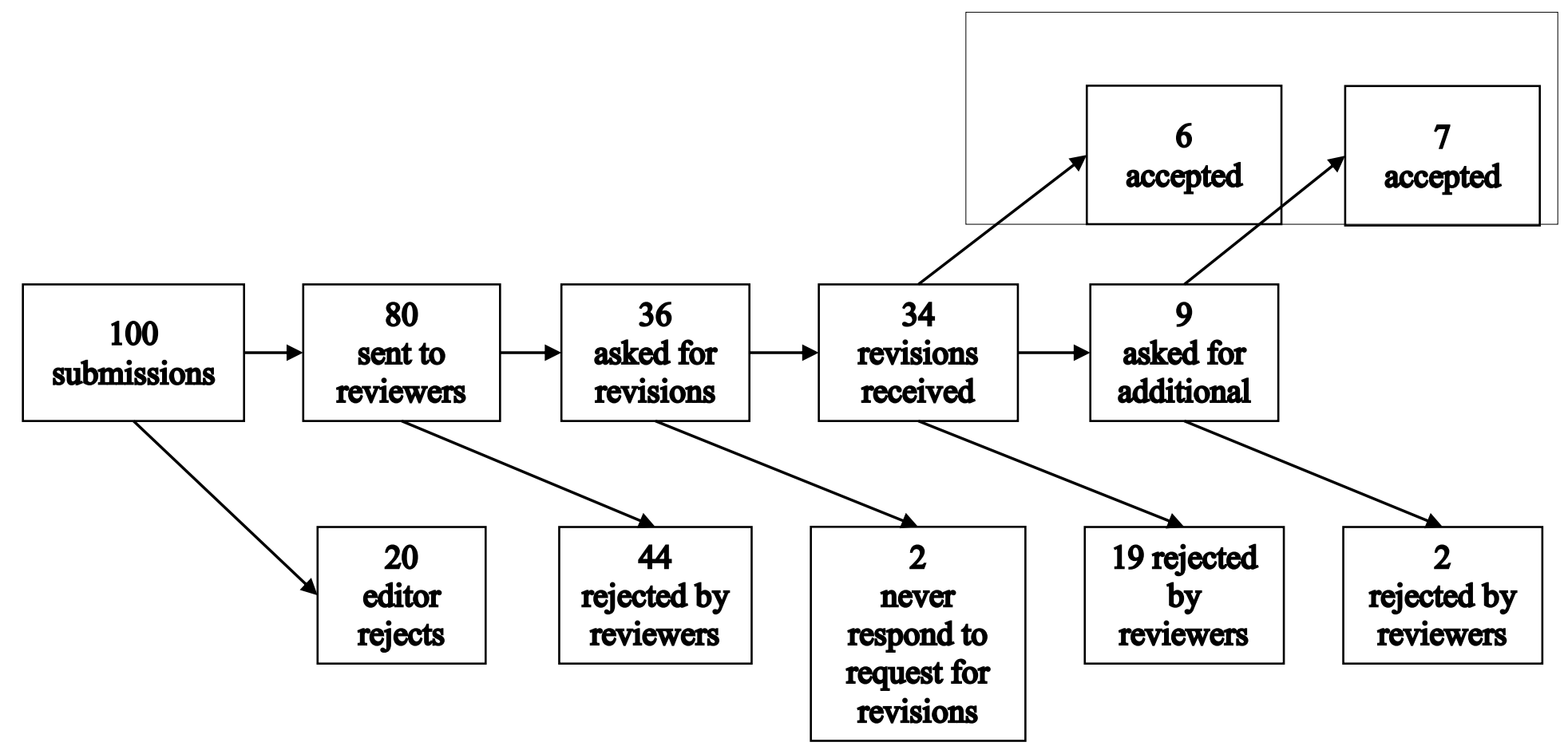

Figure 3: Typical results per 100 submissions (based on 2014 data) 
authors should bear in mind that even a minor revision does not guarantee acceptance after revision. Thus, authors should proceed with an invitation for a minor revision with the same care as they approach an invitation for a major revision.

For Industrial Marketing Management, we adhere - not always stringently, however - to the "rules" given in Figure 2. Also, if we as editors are in doubt about the quality of a manuscript, we will put it into the review process rather than rejecting the manuscript. At least then four people and not just one person will have considered the manuscript.

The typical results for the review and revision process, based on 2014 data, are that of 100 submitted manuscripts about 80 manuscripts pass through the initial evaluation process and are sent out for review. Thirty-six of those manuscripts are invited for revisions. Most authors (34 of those manuscripts) submit a revised version of their manuscript. Of those 34 manuscripts, 13 manuscripts eventually are accepted for publication (either in this revision round or in a subsequent round). The process has been depicted in Figure 3.

\section{THE PUBLICATION PROCESS}

The finer details of the publication process probably are of less interest to authors. Important, however, is that an uncorrected proof of the manuscript is sent to the corresponding author who is asked to return a corrected proof of the manuscript. Before all of this happens, the publisher sends copyright transfer to the corresponding author who must sign this transfer. Both the uncorrected proof and the corrected proof of the manuscript are placed on the journal's homepage, but once the corrected proof appears here it usually no longer will be possible to request changes to the manuscript. If, for example, authors change their affiliation, it is still their old affiliation that will appear on their manuscript. But at this point, the authors should be breathing easy: the manuscript is in, it may be soon available online (if the journal pre-publishes accepted manuscripts), and soon enough the hard copy will be published.

\section{CONCLUSIONS}

This article summaries our thoughts on the review and revision process. The process of responding to the editor's and reviewers' comments and substantially revising a manuscript to the point of acceptance can be challenging. This article has attempted to provide tips and examples of good practice to authors as they embark on this journey.

Collectively, the authors of this article have decades of experience as (section) editors. It is fair to say that many of the errors listed in this article are beginner mistakes, which probably will 
lead to a rejection in the review process, if not an outright desk rejection, and yet are preventable. A few of the obvious mistakes are the following ones: ensure there is a fit between the manuscript and the mission of the target journal; write in coherent English and enlist a professional style editor if necessary; follow all the style guidelines; respond to every single one of the reviewers' comments in the revision (seeking the help of the editor in case anything is unclear); and at least try to make the important changes suggested by the reviewers even in the case of a rejection. It is always a good idea to take advantage of the wisdom of two or three authorities in that research area who may sound harsh, but really just want to see a better quality manuscript with a more impactful contribution, and may have a good suggestion on how to do it!

We hope that this article will help authors in the process of getting their revised manuscript successfully go through the review process and hasten the road to publication. In addition, we hope this series of comments will help prospective authors prepare manuscripts that fare well in the review-and-revise process in Industrial Marketing Management and other top journals.

\section{ACKNOWLEDGMENTS}

Parts of this article previously have appeared in editorials in this journal. As such, this article has not undergone the traditional review process.

\section{REFERENCES}

LaPlaca, P., Lindgreen, A., and Vanhamme, J. (2018). How to write really good articles for premier academic journals. Industrial Marketing Management, in press. 